\title{
VIDEOS COMUNITARIOS, PROTECCION DEL DOMINIO PUBLICO Y REVOCACION DE LICENCIAS (COMENTARIO A LA SENTENCIA DEL TRIBUNAL CONSTITUCIONAL 181/1990).
}

\author{
Por \\ Félix Pérez Algar.
}

\section{Antecedentes.}

Un particular se dedicaba a la actividad de vídeo comunitario en la localidad de Callosa de Segura. Cuando solicitó la correspondiente licencia municipal, obtuvo autorización para la instalación del tendido aéreo, soporte de su actividad, pero condicionada al pago de tasas por la utilización del dominio público y a la presentación de nuevos planos. Con posterioridad, mediante dos Decretos del IImo. Sr. Alcalde de Callosa de Segura se revoca la licencia, se prohibe el tendido de cables y se impone al particular una multa de 5.000 pts.

Estos hechos van a dar origen al recurso de amparo 426/1988, recurso que fue resuelto por la Sala primera del Tribunal Constitucional en la Sentencia 181/1990, de 15 de noviembre (suplemento al Boletín Oficial del Estado no 289, de 3 de diciembre de 1990). Fue Ponente de esta Sentencia el Magistrado don Luis López Guerra.

Lo primero que hace el Tribunal Constitucional, en contra del criterio del Ministerio Fiscal, es sostener que "el ejercicio de la actividad de vídeo comunitario debe entenderse protegido por el derecho reconocido en el art. 20.1 a), de la Constitución a expresar y difundir libremente pensamientos, ideas y opiniones mediante cualquier medio de reproducción. Resulta obvio que entre los múltiples medios de comunicación hoy existentes, unos se encuentran más intimamente vinculados que otros al ejercicio de los derechos consagrados en el art. 20 de la Constitución. Ahora bien, y en el caso del vídeo comunitario, el contenido de un determinado tipo de programación (emisión de peliculas) o la mayor o menor dimensión comercial que posea no excluye que, en la actividad de vídeo comunitario, se estén defendiendo pensamientos, ideas y opiniones, directa o indirectamente". Es de observar que hasta ahora no había sido declarado de forma explicita por una sentencia del Tribunal Constitucional la inserción de la actividad de los vídeos comunitarios dentro del ámbito protegido por el artículo 20 de la Constitución. 
Sentada la anterior premisa, el Tribunal Constitucional recuerda que "los derechos fundamentales, y los del art. 20 C.E. entre ellos, no son derechos absolutos e ilimitados; por el contrario su ejercicio está sujeto tanto a límites expresos constitucionalmente como a otros que pueden fijarse para proteger o preservar otros derechos o bienes constitucionalmente protegidos". Planteada la cuestión en estos términos, lo que el Tribunal había de decidir es si el requisito del pago de tasas por la utilización del dominio público y la exigencia de aprobación por parte del Ayuntamiento de un plan técnico para el tendido de cables son o no límites constitucionalmente admisibles al :derecho a la libertad de información que, en definitiva, implica el vídeo comunitario.

\section{La protección del dominio público.}

Los dos requisitos, las tasas y el plan técnico, van a resultar constitucionalmente legítimos porque tanto uno como otro son medios de protección del dominio público. El Tribunal Constitucional afirma que "Ia justificación que poseen ambas exigencias resulta clara: la protección del uso legítimo de bienes de dominio público, constitucionalmente protegido por el art. 132 de la Norma Fundamental". De este modo, "resulta perfectamente lícita la protección del dominio público que acarrea como consecuencia el establecimiento de ciertas condiciones de ejercicio a derechos como los que pretendía ejercitar el actor. Dicho de otra manera, si bien es cierto que los derechos del art. 20 C.E. incluyen el derecho a crear medios y soportes de difusión, como reconociera la STC 12/1982, tal derecho no es absoluto y debe compaginarse con la protección de otros bienes constitucionalmente relevantes. Ello justifica la exigencia de requisitos como los que en su día impuso el Ayuntamiento de Callosa del Segura al actor".

De esta forma, queda explícita y rotundamente declarada la competencia municipal para imponer condiciones al ejercicio de la actividad de los vídeos comunitarios. Condiciones que pueden ser no sólo las de la exigencia de tasas y la presentación de un proyecto técnico, sino también todas aquellas necesarias para una debida protección del dominio público.

Ahora bien, es de advertir que el Tribunal Constitucional no admite que los Ayuntamientos puedan imponer requisitos al ejercicio de la actividad del vídeo comunitario de forma incondicionada. Aunque el recurrente no entra en este punto, el Tribunal, probablemente para dejar clara su doctrina, se ocupa de comprobar que en el caso planteado 
las facultades municipales de protección del dominio público "no resultan abusivas o desproporcionadas". Porque, en efecto, la autoridad municipal puede limitar el ejercicio del derecho a la libertad de información para proteger el dominio público, pero lo que no puede hacer es utilizar este título competencial como excusa para lograr otros fines distintos.

La competencia del Ayuntamiento lo es para proteger el dominio público, y no para otra cosa. Por esto, tiene que existir una proporción entre la medida adoptada y el fin para el cual se atribuye la competencia. Si la medida adoptada excede de la finalidad perseguida, el resultado es que se cumplen otros objetivos distintos de los de la protección del dominio público, con lo que la medida resulta ilegal. Así por ejemplo, no pueden imponerse limitaciones que, con el pretexto de protección del dominio público, pretendan en realidad impedir la actividad en si misma considerada por estar el Ayuntamiento en contra de su ejercicio. La fijación de unos precios públicos desorbitados -puesto que parece que esta figura, en vez de la de la tasa, es la que debe aplicarse tras la Ley Reguladora de las Haciendas Locales- o la exigencia de unos requisitos técnicos desproporcionados, privan de legitimidad a la intervención municipal.

En definitiva, los Ayuntamientos no tienen una posibilidad de control total, genérico e indeterminado, sobre la existencia o inexistencia de los vídeos comunitarios. Tienen competencias para incidir en tal actividad en la medida en la cual deban proteger el dominio público $e$, incluso, otros bienes constitucionalmente garantizados cuya defensa les competa. De este modo, la frontera entre la legalidad o la ilegalidad de las decisiones municipales dependerá de la concordancia de tales decisiones con la finalidad para la que tienen atribuida su competencia.

\section{La revocación de licencias. El estado de la cuestión.}

Con las consideraciones anteriores quedan resueltos los aspectos fundamentales de la cuestión de la posibilidad y límites de la intervención municipal en la actividad de los vídeos comunitarios. Pero en el caso planteado en la Sentencia 181/1990 se suscita otro tema, distinto del anterior, de indudable interés: los aspectos constitucionales de la revocación de licencias.

De los antecedentes de hecho resulta que se concedió una licencia en la cual se incluían varias condiciones que, al resultar incumplidas, 
dieron origen a la revocación de la licencia. Pero el recurrente argumenta que esta revocación se hizo sin habérsele dado a conocer los hechos que se le imputaban, sin audiencia y sin oportunidad de defensa, es decir, sin respetar las garantías contenidas en el artículo 24 de la Constitución.

El Tribunal Constitucional tiene reiteradamente declarado que las garantías contenidas en el artículo 24 de la Constitución son aplicables no sólo a los procedimientos jurisdiccionales, sino también a los administrativos de naturaleza sancionadora "en la medida necesaria para preservar los valores esenciales que se encuentran en la base del precepto, y la seguridad jurídica que garantiza el art. 9 de la Constitución" (Sentencia 18/1981). De este. modo, el problema básico planteado consistia en decidir si en las revocaciones de licencias que tengan naturaleza sancionadora se aplican o no los principios contenidos en el artículo 24 de la Constitución.

La Sentencia que comentamos es la segunda que aborda la situación constitucional de la revocación de licencias. Antes de ella, la también reciente Sentencia 61/1990, de 29 de marzo (suplemento al Boletín Oficial del Estado no 107, de 4 de mayo de 1990) abordó la revocación, explícitamente adoptada como medida sancionadora, de una licencia de Detective privado. En este caso, lo que se denunciaba era una infracción del artículo 25 de la norma constitucional, reiteradamente declarado aplicable a las sanciones administrativas, en la medida en la cual la revocación-sanción se habia producido aplicando una norma cuyo rango era simplemente el de Orden Ministerial. Dado que el artículo 25 de la Constitución garantiza, entre otras cosas, la existencia de una norma de adecuado rango (en definitiva, una Ley), la revocación fue declarada nula.

De este modo, al llegar a la Sentencia 181/1990 ya estaba declarada la aplicabilidad de los principios del artículo 25 de la Constitución a la revocación de las licencias cuando esta revocación se produce con carácter sancionador. Faltaba por decidir si son también. apliçables a la revocación-sanción los principios contenidos en el artículo 24 de la Constitución. Por otra parte, y como por lo demás sucede en tantas ocasiones, hay veces que una cuestión que es prácticamente incidental en una Sentencia, se convierte en cuestión sustantiva en otra. Asi, mientras una Sentencia descubre que el problema existe, la siguiente establece los puntos fundamentales para la consolidación y desarrollo de una línea jurisprudencial específica en torno al problema planteado. Esto último es lo que sucede en la Sentencia 181/1990. 


\section{Requisitos para la revocación de la licencia.}

La aplicabilidad de los principios recogidos en el artículos 24 de la Constitución a la revocación de licencias, siempre "en la medida necesaria para preservar los valores que se encuentran en la base del precepto, y la seguridad jurídica que garantiza el art. 9 de la Constitución" es cosa que, tras la Sentencia 181/1990, no parece dudosa. Aunque en el caso planteado no se aplican tales principios, ello no resulta de que tales principios no fueran en sí mismos aplicables, sino de que no se daban las circunstancias necesarias para que tales garantías hubieran de estar presentes. En efecto, el Tribunal. Constitucional deja claro (fundamento jurídico $5^{\circ}$ ) que los principios del artículo 24 de la Constitución son aplicables a la revocación-sanción, pero afirma que en el caso no se encontraba ante una revocación sanción, sino ante una revocación ordinaria.

Particularmente interesante resulta la doctrina que sienta el Tribunal Constitucional para llegar a la conclusión de la no aplicabilidad en el caso de los principios del artículo 24 de la Constitución: "La revocación de una licencia constituye una actuación administrativa que en ocasiones tiene una dimensión sancionadora y en otras no. En efecto, en tanto en cuanto la revocación de una licencia, al igual que su no otorgamiento, se base en el incumplimiento de los requisitos establecidos por el ordenamiento para el desarrollo de la actividad pretendida, no cabe afirmar que se esté ante una actividad sancionadora, sino de simple aplicación de ese ordenamiento por parte de la Administración competente, tarea en el que el margen de apreciación es escaso. En otros casos, en cambio, la revocación de la licencia responde a un más amplio margen de apreciación en manos de la Administración, que se ve posibilitada para valorar determinadas conductas como contrarias al ordenamiento; en estos casos, típicos de la denominada por la doctrina 'revocación-sanción' este último elemento aparece mucho más patente...".

No obstante, el Tribunal Constitucional reconoce que "Ciertamente, trazar una línea divisoria entre ambas medidas, con pretensión de validez general resulta poco menos que imposible $y$, en consecuencia, calificar unas medidas concretas como sanción o simple aplicación de las normas administrativas habilitantes para la gestión de una actividad requiere tener en cuenta las circunstancias de cada caso".

Ahora bien, por lo general el problema futuro no va a ser si se aplican o no los principios de los artículos 24 y 25 de la Constitución en la revocación de carácter sancionador de las licencias, cuestión que parece resuelta por las Sentencias 61/1990 y 181/1990, sino que la 
dificultad reside en algo más práctico: cómo decidir si estamos o no ante una revocación-sanción. No toda revocación es sancionadora; hay revocaciones "ordinarias" en las cuales no necesariamente deben aplicarse los principios de los artículos 24 y 25 de la Constitución en la medida en que tales revocaciones no tienen naturaleza sancionadora. De este modo, lo que hay que precisar es cómo se distinguen unas revocaciones de otras, en qué casos unas garantías son imprescindibles $y$ en qué casos no lo son. Una revocación sancionadora y otra que no lo es tienen, además de una distinta naturaleza, un régimen jurídico diferente desde el punto de vista de las garantías constitucionales que les son aplicables.

Sentada la premisa de que el régimen jurídico es distinto en las revocaciones en función de su naturaleza sancionadora o no sancionadora, y aunque evidentemente haya que estar a las circunstancias de cada litigio, conviene intentar definir los criterios de acuerdo con los cuales se puede decidir el carácter sancionador de la revocación y, en consecuencia, la aplicabilidad o no de las garantías constitucionales.

En principio, parece que el Tribunal Constitucional, en el caso resuelto por la Sentencia 181/1990, se inclina por el examen de las posibilidades de apreciación que tenga la Administración pública: "no existiendo datos que hagan presumir que la decisión adoptada derive de la valoración discrecional de conductas del afectado, no parece que pueda calificarse de sanción la medida adoptada ni en cuanto a dejar la licencia sin efecto ni en lo que se refiere a la suspensión del tendido de cables".

Estas afirmaciones, a pesar de algunas dificultades terminológicas (no parece que la actividad sancionadora sea una actividad discrecional) parecen apuntar hacia un criterio relativamente preciso o, cuanto menos, indicativo del carácter de la revocación. Existen casos en los cuales la licencia se revoca por condiciones puramente objetivas; por la relevancia que tiene la actividad autorizada para los terceros o para un determinado entorno físico. En estos supuestos, para nada importa la conducta del titular. Es irrelevante su buena o mala fe, su pericia o su negligencia. Lo importante es que una determinada cosa se haga porque eso tiene consecuencias para las personas o para su entorno físico.

En este tipo de casos, la Administración no tiene que valorar de forma positiva o negativa el comportamiento del titular de la licencia, sino exclusivamente los resultados objetivos de su comportamiento. Se trata de que un determinado requisito, en si mismo objetivo y relevante para los terceros o el entorno, se haya cumplido o no. Pues 
bien, en estas ocasiones la eventual revocación de la licencia no es sancionadora, puesto que no castiga una conducta reprobable, sino que se limita a comprobar el incumplimiento objetivo de un requisito objetivo de la actividad.

Otra cosa sucede cuando la revocación de la licencia se hace tras el examen de la conducta especifica seguida por una determinada persona. Ya no hay aqui un incumplimiento de requisitos objetivos, sino una valoración negativa de un cierto comportamiento que ha seguido el titular de la licencia, valoración que es, además, la causa de la revocación de la licencia. En efecto, en este caso se analiza una conducta para determinar si ésta es reprobable o no $y$, en su caso, actuar en consecuencia: castigando el comportamiento mediante la revocación de la licencia. De este modo, la revocación sí es claramente una sanción por un comportamiento subjetivo en sí mismo considerado.

Obsérvese cómo las garantías previstas en los artículos 24 y 25 de la Constitución, y en general los principios del Derecho sancionador, sólo tienen sentido cuando se enjuician comportamientos personales, subjetivos, pero no cuando se enjuicia el incumplimiento de los elementos objetivos. Así por ejemplo, para saber si un tendido de cables afecta o no a la seguridad de la población en nada influye el principio "in dubio pro reo": lo importante es si, efectivamente, el tendido de cables afecta o no a la seguridad de la población. Pero si de lo que se trata es de acusar a alguien de haber hecho alguna cosa de la que se pueden derivar consecuencias desfavorables para él, entonces sí que tiene pleno sentido aplicar un conjunto de garantías que, en definitiva, están pensadas para que todo español tenga derecho a defenderse de los reproches que puedan hacerse de su comportamiento.

\section{Conclusión.}

Toda sentencia novedosa deja necesariamente puntos sin aclarar. Probablemente el propio Tribunal Constitucional $u$ otros Tribunales diferentes habrán de precisar algunos aspectos que en la Sentencia $181 / 1990$ quedan enunciados, pero no resueltos hasta sus últimas consecuencias. Sin perjuicio de ello, la definición de las competencias municipales en el establecimiento de vídeos comunitarios ( $y$, en general, en el derecho fundamental a la libertad de información), así como las precisiones realizadas en el novedoso tema de la revocación de las licencias desde el punto de vista constitucional, convierten a esta Sentencia en un interesante punto de partida de otras decisiones posteriores. 
REALA-1991, núm. 252. PEREZ ALGAR, FELIX. VIDEOS COMUNITARIOS, PROTECCION DEL DO...

REALA-1991, núm. 252. PEREZ ALGAR, FELIX. VIDEOS COMUNITARIOS, PROTECCION DEL DO... 